\title{
A Comparative Study on Substation Types and Network Layouts in Connection with Low-Energy District Heating Systems
}

\author{
Tol, Hakan; Svendsen, Svend
}

Published in:

Energy Conversion and Management

Link to article, DOI:

10.1016/j.enconman.2012.04.022

Publication date:

2012

Document Version

Early version, also known as pre-print

Link back to DTU Orbit

Citation (APA):

Tol, H., \& Svendsen, S. (2012). A Comparative Study on Substation Types and Network Layouts in Connection with Low-Energy District Heating Systems. Energy Conversion and Management, 64, 551-561.

https://doi.org/10.1016/j.enconman.2012.04.022

\section{General rights}

Copyright and moral rights for the publications made accessible in the public portal are retained by the authors and/or other copyright owners and it is a condition of accessing publications that users recognise and abide by the legal requirements associated with these rights.

- Users may download and print one copy of any publication from the public portal for the purpose of private study or research.

- You may not further distribute the material or use it for any profit-making activity or commercial gain

- You may freely distribute the URL identifying the publication in the public portal

If you believe that this document breaches copyright please contact us providing details, and we will remove access to the work immediately and investigate your claim 


\title{
A Comparative Study on Substation Types and Network Layouts in Connection with Low-Energy District Heating Systems
}

\author{
Tol H. İ. ${ }^{1,}$, , Svendsen S. ${ }^{1}$ \\ ${ }^{1}$ Technical University of Denmark, Department of Civil Engineering, Section of Building Physics and Services, \\ Brovej, Building 118 DK-2800, Kgs. Lyngby, Denmark
}

\begin{abstract}
The study deals with low-energy district heating (DH) networks operating in low temperatures such as $55^{\circ} \mathrm{C}$ in terms of supply and $25^{\circ} \mathrm{C}$ in terms of return. The network layout, additional booster pumps, and different substation types such as storage tanks either equipped or not equipped in domestic hot water production site were examined. Effects of booster pumps on pipe dimensions in the latter case were investigated. Temperature drops during the summer months due to low heat demands of consumers were explored. Use of approaches such as looped networks and branched network layouts with bypasses for end-consumers were also studied, heat loss from these networks and the drop in temperature in the heat-carrier-supply medium being compared.
\end{abstract}

Keywords: district heating; low temperature; substation type; branched network; looped network; booster pump.

* Corresponding author. Tel: +45 452550 27; fax: +45 45883282.

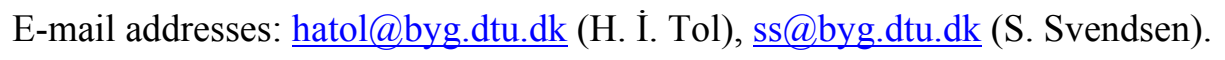

\section{INTRODUCTION}

Energy supply systems based on renewable energy sources have been of considerable interest to policy makers concerned with finding long-term energy solutions, due to such systems being more environmentally friendly than those leading to depletion of fossil-fuels [1-3]. The possibility has been considered of employing District Heating (DH) systems in conjunction with renewable energy sources as a long-term energy solution. This is partly in view of the 
ease with which DH systems can be connected with any type of heat source [4-7]. Successful examples of employing extremely low supply temperatures in low-energy $\mathrm{DH}$ systems, $55^{\circ} \mathrm{C}$ for example and $25^{\circ} \mathrm{C}$ for return temperatures have been demonstrated in case projects in Lystrup, Denmark [8-10], and in the SSE Greenwatt Way development project in Slough in the UK $[11,12]$. Various advantages in the use of low operating temperatures have been shown, such as reduction in overall heat loss from the DH network, increased efficiency in heat extraction at the heat source, and the exploitation of low temperature renewable energy sources such as geothermal sources, solar energy etc. and of waste heat from industry, which otherwise be lost [13-15].

In addition to the benefits achieved by use of low operating temperatures, there are expected to be gains achieved through determining the most energy-efficient dimensioning method or methods to be used in low-energy DH systems. In an earlier study [16], an optimization method was reported, one based in part on earlier studies at our department [17-20]. The method in question aimed at minimizing heat loss from the DH network through reducing the pipe dimensions in each pipe segment of the network. Once the main pump of the DH network is dimensioned so as to provide a certain amount of head lift, as determined on the basis of pressure loss along the critical route, the network can compensate for pressure losses along the other routes in the DH network [21]. An optimization algorithm that was developed facilitated the head lift the pump provided being utilized as much as possible along each route, not simply the critical one $[16,22]$. The cost impact of pumping was found to be extremely low in comparison both to heat loss from the DH network and to the pipe investment costs when low-energy DH systems using twin pipes $[8,10]$. The optimization method was, therefore, designed with the aim of minimizing heat losses from the $\mathrm{DH}$ network and maximizing the reliability of the system. It also prevented the pressure losses from exceeding the system's upper static pressure limit. In order to supply the heating that consumers needed, the DH net- 
work was dimensioned in accordance with the lowest pressure difference that would be viable, one of about $50 \mathrm{kPa}$, its exact value being unique for the substation of each consumer.

The work presented in the paper addresses two major topics the authors have taken up earlier $[16,23]$. Emphasis is placed in the present paper on details of the analyses conducted of the effects of the different types of substations and of the network layouts involved. The two major topics considered here are 1) the effects of the substations of different types and of additional booster pumps in the DH network on the pipe dimensions employed and 2) the excessive temperature drop observed in the supply line during the summer months, as viewed in light of the differing heat consumption profiles of consumers during that period.

\section{METHODS}

The investigations described were carried out within a genuine case study conducted in Trekroner (a suburban area of the Roskilde Municipality in Denmark) concerned with 165 lowenergy houses to be built, for which it was planned that they would be provided with a lowenergy DH network. The network was to have an overall length of $1.2 \mathrm{~km}$ and of $1.4 \mathrm{~km}$ in the case of a branched and of a looped layout, respectively, that were planned to be dimensioned in accordance with twin pipes. The design limit of maximum static pressure was restrained at 10 bara with the use of twin pipes in the DH network. Each consumer was assumed to have the same reference house, appropriate for the low-energy class as defined by the software $\mathrm{Be} 06$ [24].

\subsection{Effects of the Substation Types and the Booster Pump on the Pipe Dimen- sions}

Studies concerning the substation types and the booster pump were only carried out for the branched DH network layout (Figure 1). The overall heat load for consumers depended on the consumers' heat consumption profile and Domestic Hot Water (DHW) consumption, as well 
as on the type of the substation established at each consumer site [25]. Both of the substations considered in the study made use of the same type of heat exchanger and control system in regard to DHW production. Each substation was assumed to supply heat to one consumer only, although in some cases substations can be considered to supply several consumers [26]. The units for space heating (radiators, floor heating, etc.) were assumed to be connected with the DH network directly and for both types of substations to have a fixed heat demand of 3 $\mathrm{kW}$. The substations were considered to be equipped with differential pressure control valves that adjusted the flow on the primary side (where the DH medium is circulated), in accordance with the heat demand requirements that apply which are aimed at achieving a hydraulically balanced distribution throughout the DH network [27, 28] (More detailed information regarding the substations with the types involved, given in the following two sub-sections, can be obtained from studies [8-10, 14, 29, 30]. 


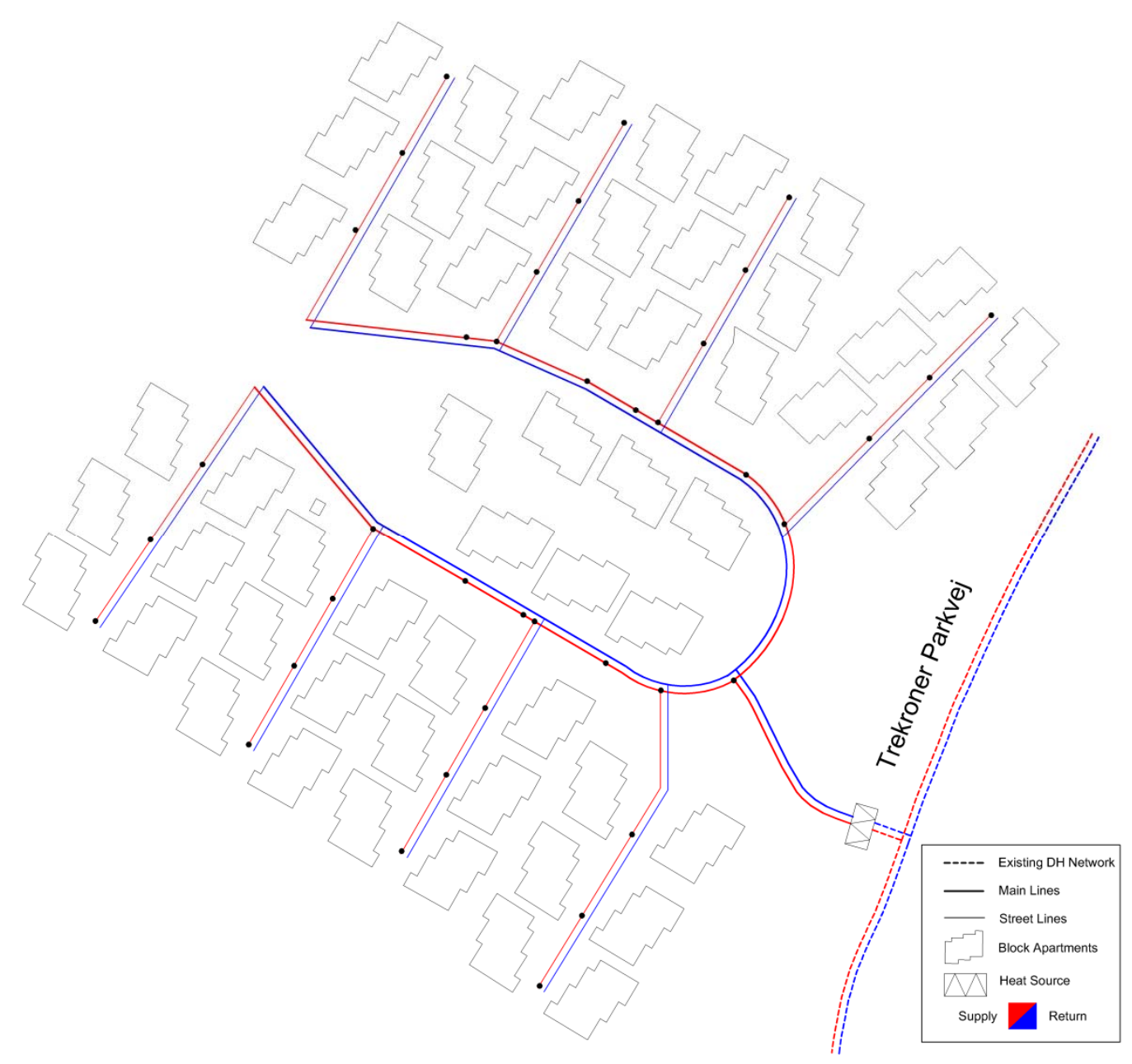

Figure 1. Branched network layout considered for use in the Trekroner Area.

\subsubsection{Substation Type 1}

This type of substation was equipped with a storage tank having a capacity of 1201 for DHW production (Figure 2). In this configuration of the substation, the storage tank is located on the primary side, where the $\mathrm{DH}$ heat carrier medium is circulated, so as to avoid the risk of legionella growth. The heat supply carrier medium is stored in the storage tank during charging of the tank. When DHW is being used by a consumer, the stored heat carrier medium is considered to be circulating through the heat exchanger of the DHW production unit. The flow rate in charging the storage tank is $75 \mathrm{l} / \mathrm{h}$ at the most, equivalent for DHW to $3 \mathrm{~kW}$ of heat demand, supplied by the DH network [10]. 


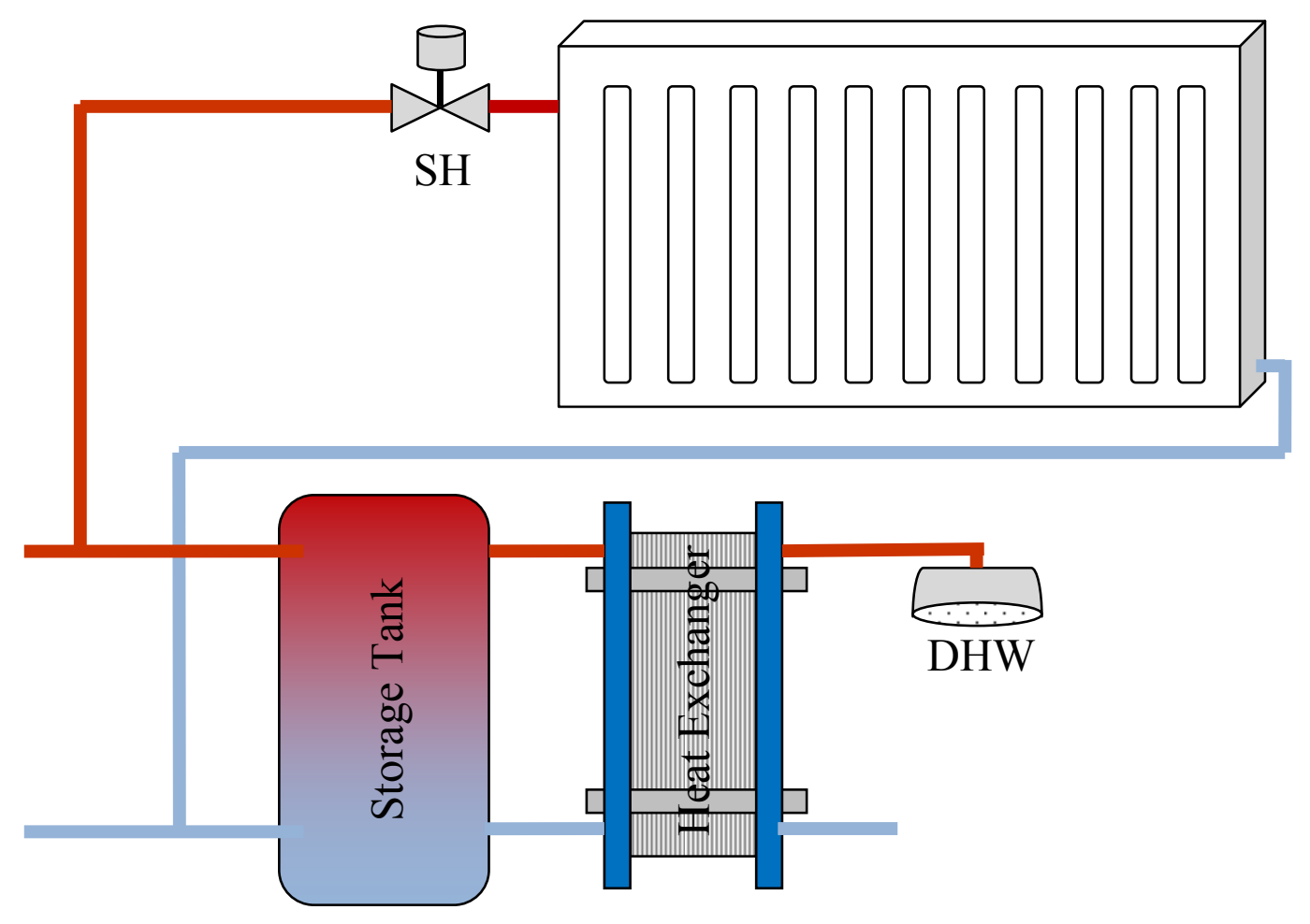

Figure 2. Diagram of Substation Type 1.

\subsubsection{Substation Type 2}

In this substation, configuration of the DH network was defined as being connected directly with the heat exchanger of the DHW production unit (though no storage tank, in fact, was installed), as shown in Figure 3. The heat demand that DHW production created was set to 32 $\mathrm{kW}$, based on data reported in studies. 


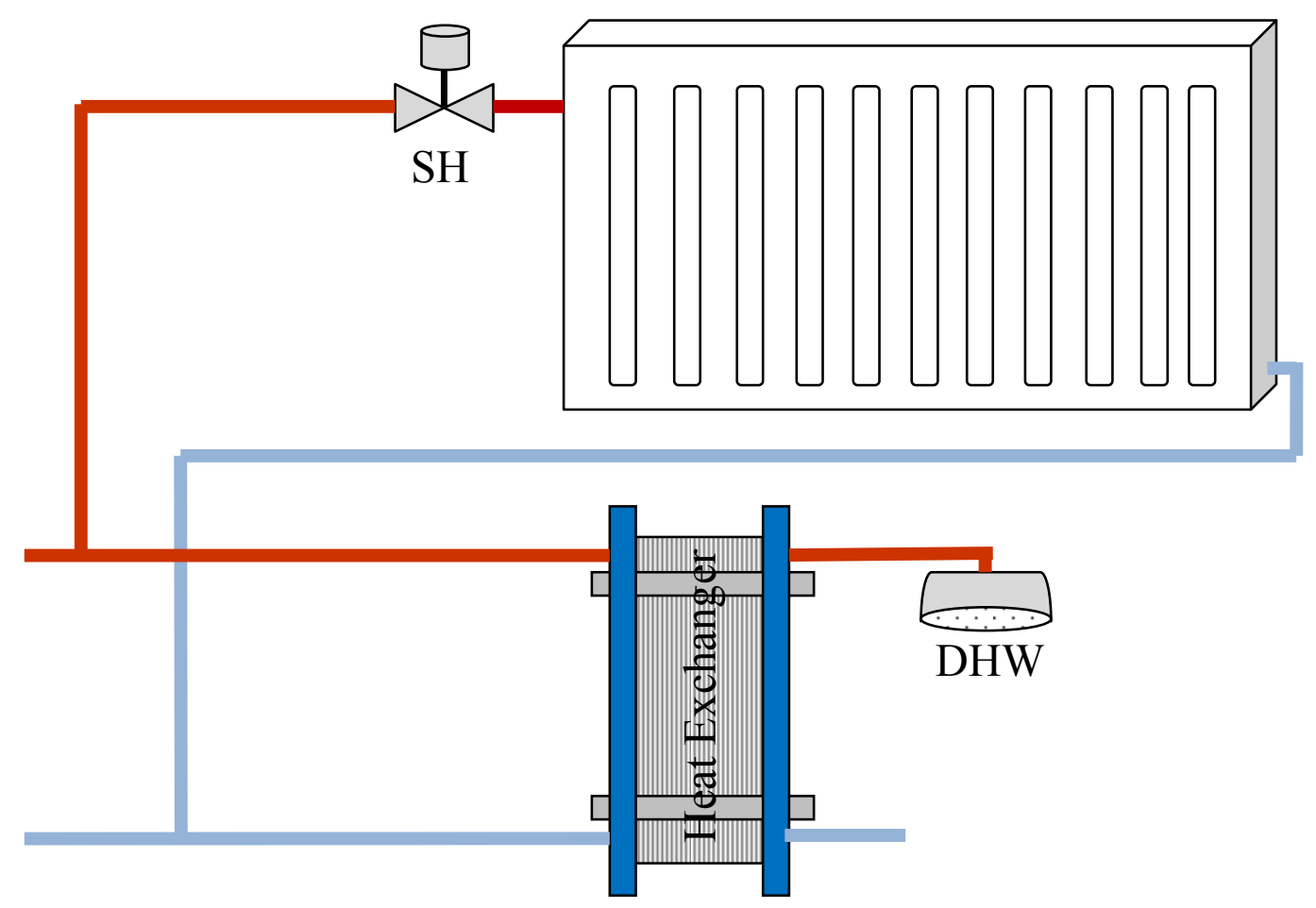

Figure 3. Diagram of Substation Type 2.

\subsubsection{Booster Pump}

The degree of utilisation of booster pumps varies widely within distribution networks. Traditionally, a booster pump is used to discharge the medium stored in an atmospheric storage tank into a separate, closed and/or high-service distribution network [27]. In the present study, we considered using booster pumps to increase the head lift, designed to be utilised as much as possible in the optimization method employed, with the aim of reducing the pipe dimensions. Increasing the pressure difference between the supply and the return lines by means of the extra head lift that the booster pumps provided made it possible to reduce the pipe dimensions further in a low-energy DH network considered as supplying heat to consumers from a Type 2 Substation. In a closed distribution system, the additional head lift provided needs to be checked regarding whether the overall static pressure at the location where the booster pumps are installed exceeds the maximum allowable static pressure level, the residual pressure level provided by the main pump station also needing to be taken into account in connection with this. In this basis of providing extra head lift; the branched network layout was 
formed with additional booster pumps equipped at the start of the pipe segments in each street, as shown in Figure 4. The overall static pressure levels, involving the residual and additional head lift provided, respectively, from the main pump station and from the booster pumps established, were checked in each street. No booster pumps were installed in the streets exceeding the overall static pressure beyond the design limit of 10 bara.

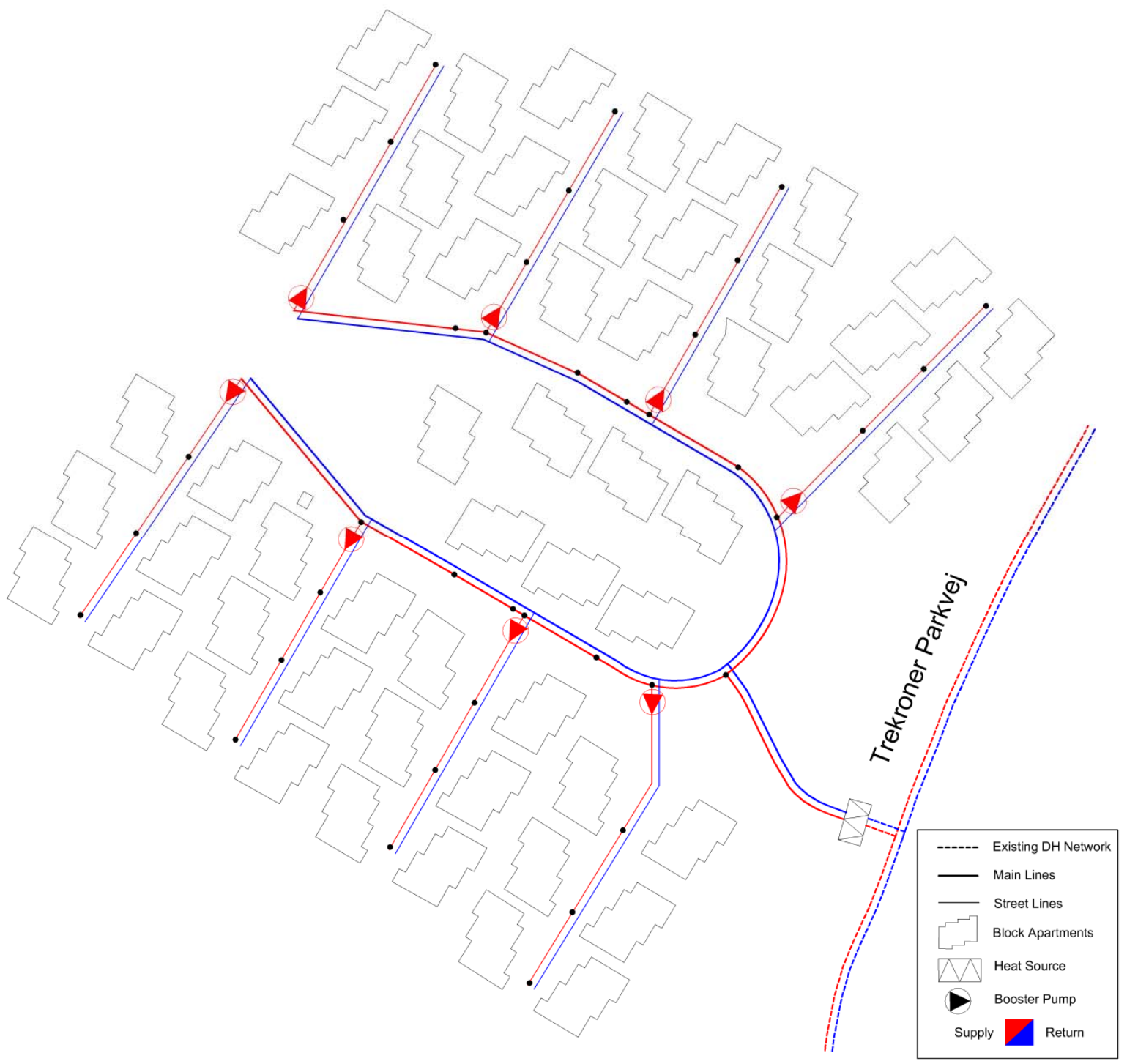

Figure 4. Branched layout in which booster pumps are located on the supply line at the starting section of each of the streets involved. 


\subsection{Preventing Temperature Drop in the Summer Months}

The consumers do not necessarily need space heating during the summer months. Also, many of them are away on holiday during at least part of that time, reducing the overall DHW consumption. Because of the heat demand being low, no space heating being needed and the reduced DHW needs, the heat carrier medium tends to be exposed to long waiting times before being consumed, leading to the supply heat carrier medium's temperature being markedly reduced [31-33]. Regarding the summer months, there are two matters to be considered in particular: the adequacy of the supply temperature the consumers are provided with, and the heat loss that occurs from the DH network because of the long waiting time of the heat carrier medium. It could be worthwhile to investigate the importance of both matters for maintaining the reliability of supply, so as to avoid excessive temperature drops within the DH network, as regards both a) the branched portion of the DH network with its bypasses equipped at the endconsumers and b) the looped portion of it, without bypasses.

\subsubsection{Branched DH Networks}

A branched network layout is widely used in the distribution networks of DH systems as well as in draining and irrigation systems. Such layouts are also observable in natural objects such as blood vessels and trees $[34,35]$. Branched (also known as tree-like) DH networks are formed in layouts permitting a unidirectional flow from the heat source to the end-consumers (Figure 1). In a layout of this type there are only two pipe segments connected to each interior node and a unidirectional flow from the root node (the node without any preceding nodes i.e, the heat source) towards the leaf nodes (the nodes without any successor nodes - i.e. the end consumers) $[20,36]$. The traditional way of determining the heat load on each pipe segment is to sum all of the heat loads of the successor nodes [37]. In the present study use of a simultaneity factor which is a function of the cumulative number of consumers for each pipe segment was considered. This enables there to be a descending succession of pipe diameters 
from the heat source to the end consumers, larger diameters being followed by smaller diameters, therefore [38].

In such a branched network layout, thermostatic bypass units were to be inserted at the leafnodes in each route of the DH network. Such bypass units become activated when the supply temperature decreases to a certain point, which in the present study was set to $50{ }^{\circ} \mathrm{C}$, there being a dead band at $4{ }^{\circ} \mathrm{C}$ and a maximum flow level of $0.056 \mathrm{~kg} / \mathrm{s}$, to be used in hydraulic and thermal simulation software Termis software [39]. The supply heat carrier medium, when cooled down, is directed through the bypass units to the return line, to be sent back to the heat source.

\subsubsection{Looped DH Networks}

It was decided that use would be made in part of looped layouts as distribution networks due to their providing greater security of supply than branched layouts do $[37,40]$. The loops in the pipe segments were in the form of closed paths composed of branches, such that each heat-demanding-node had a number of alternative paths to be supplied by the heat carrier medium of neighbouring nodes [38]. Use of a looped layout results in the direction of flow being determined by the shortest (least resistant) path when delivering the heat carrier medium to the heat-demanding-nodes. For a looped layout there is some uncertainty, however, regarding the direction of flow, which is affected by the dynamics of heat consumption in the heat demanding nodes. Since each looped layout is a closed branched path, the piping network in such a looped layout supplies heat to a greater number of consumers in a given district than a branched layout does. Accordingly, supplying a greater number of consumers within such a looped layout can lead to the circulation of the DH heat carrier medium occurring in a completely natural way, through heat consumption by the consumers. In the present study, the DH network was provided with a looped layout without any bypasses (Figure 5). It should be emphasized that a network being looped can result in its being greater in length than a corre- 
sponding branched one, due to the additional pipe segments used to form the closed path of branches there $[38,40]$. The dimensions of the pipe segments used to link the branches in forming the looped layout were selected on the basis of the maximum diameter of the pipe segments that were to be linked together.

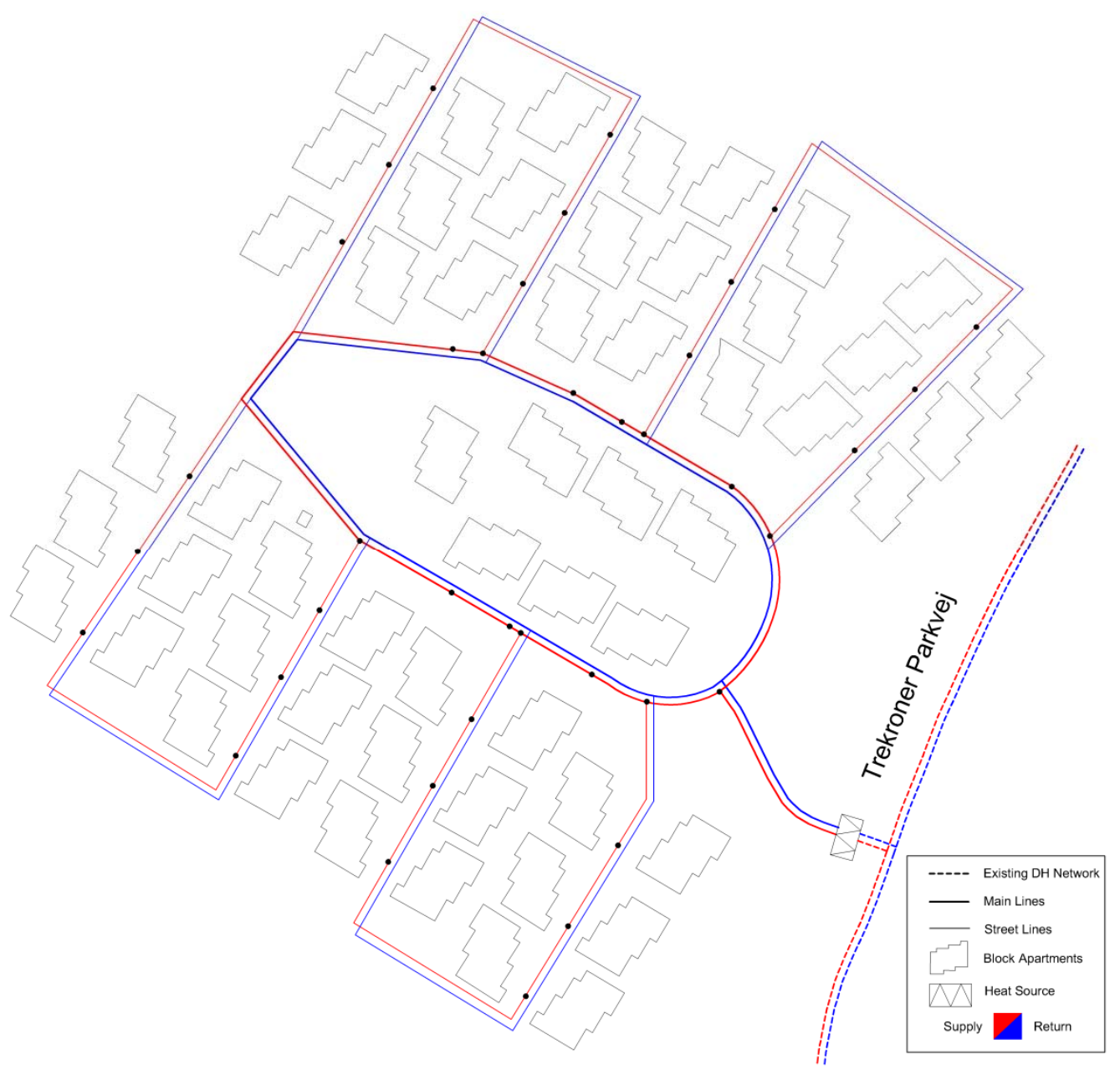

Figure 5. Looped network layout considered for use in the Trekroner area.

\subsection{Dynamic Analyses Representing Summer Situations}

The dynamics of heat consumption by the consumers affects operation of the DH system considerably through producing variations in critical routes and in the flow conditions present $[20,41,42]$. Accordingly several scenarios, representing different types of consumer behaviour, were generated to investigate the energy efficiency of different network layouts [43]. In generating the scenarios, account was taken of a wide variety of urban heat consumption pro- 
files for the summer months, including lack of need of $\mathrm{SH}$, the vacation-intended absence of some consumers, and the DHW needs of consumers presents in the district (entirely on the basis of the simultaneity factor) [42]. The scenarios generated were used then as input data to the DH model for dynamic analyses, carried out by the Termis software [39], for comparing the energy efficiency of the layouts in terms of heat loss from the DH network and temperature drops that occurred in supplying the heat-demanding nodes.

Also, the basic idea of degree-hours, described in detail in [44], was used in assessing the degree of satisfaction of consumers regarding the supply temperature [44]. A degree-minutes formulation based on degree-hours was defined to investigate the deficiencies in the supply temperature arrived at the heat-demanding consumers through the periods of time covered in dynamic simulations. Accordingly, the supply temperature arriving at the heat-demanding consumers below a certain base temperature level of $50{ }^{\circ} \mathrm{C}$ were investigated by use of degree-minutes formulation. In this way, in comparing the two different layouts described in the previous section (2.2), the dissatisfaction of consumers regarding the supply temperature can be followed comprehensively during periods studied by means of dynamic analyses.

\section{RESULTS}

In the present paper, two aspects of the utilisation of a low-energy DH system in the area in question were examined: 1) the effects of differing substation types and of additional booster pumps on pipe diameters, and 2) the effects of the network layout on the energy efficiency of heat distribution during the summer months.

\subsection{Effects of Substation Types and of Booster Pumps}

Figure 6 shows heat load values, calculated for separate pipe segments dependent on the cumulative numbers of consumers. These were used in calculating the simultaneity factor applying to the Trekroner low-energy DH network. The various pipe segments differed in the rate 
of reduction in heat load obtained with use of Substation Type 2 as compared with that obtained with use of Substation Type 1. For example, for Substation Type 2 the rate of reduction in heat load was found to be $30 \%$ for the main pipe segment designated as " 1 ", whereas the rate reached $70 \%$ for the end branch (the last pipe segment) in each route. Each end branch pipe segment was defined as supplying heat to six consumers.

The branched network consisted of 38 pipe segments in the configuration consisting of separate routes, each composed of sequences of pipe segments in reverse-hierarchical order, as shown in Table 1. The same pipe-segment order applies to the other tables (Table 2, Table 3, and Table 4) as well with the same branched network layout.

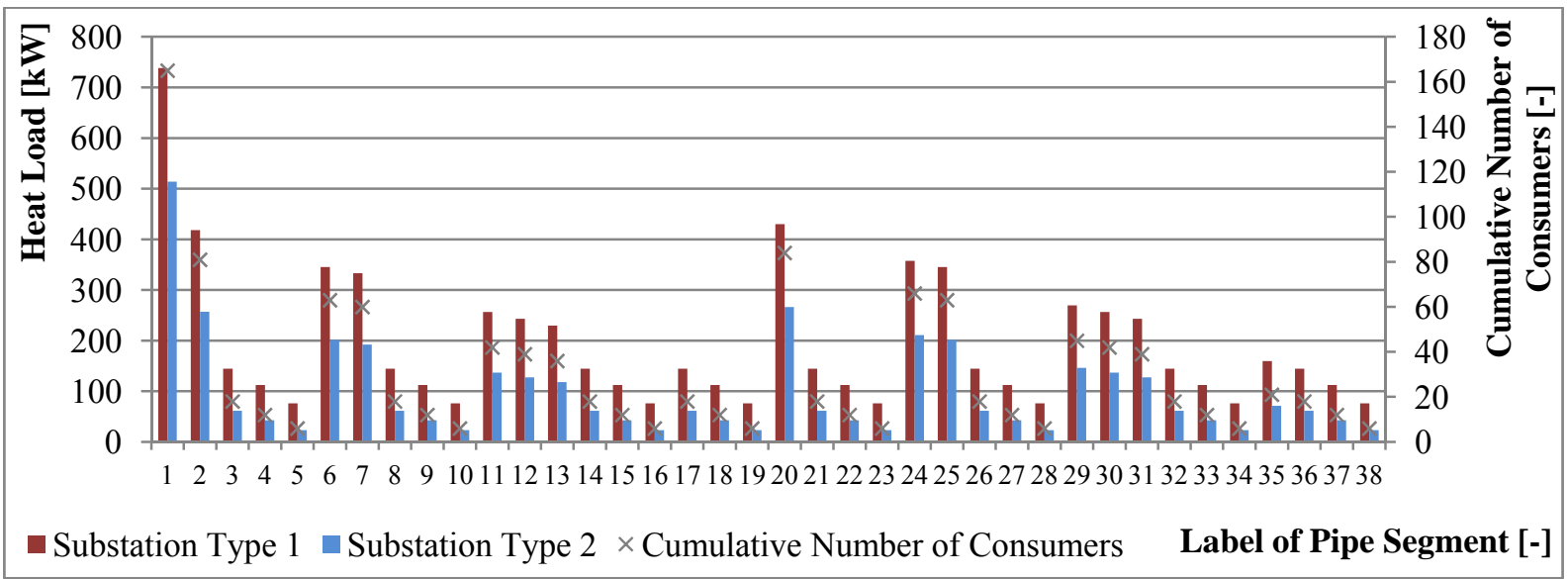

Figure 6. Effects of substation types on heat load values determined for each pipe segment on the basis of the simultaneity factor, shown as a function of cumulative numbers of consumers. 
Table 1. Configuration of routes as sequences of pipe segments, the lengths of the different pipe segments being indicated.

\begin{tabular}{|c|c|c|c|c|c|c|c|c|c|c|c|c|}
\hline & & $1^{\mathrm{a}}$ & 2 & 3 & 4 & 5 & 6 & 7 & 8 & 9 & 10 & 11 \\
\hline \multirow{2}{*}{ Route 1} & Pipe Segment [-] & 5 & 4 & 3 & 2 & 1 & - & - & - & - & - & - \\
\hline & Length [m] & 24.4 & 21.6 & 41 & 19 & 66 & - & - & - & - & - & - \\
\hline \multirow{2}{*}{ Route 2} & Pipe Segment & 10 & 9 & 8 & 7 & 6 & 2 & 1 & - & - & - & - \\
\hline & Length [m] & 22.8 & 23 & 23.4 & 37.4 & 35.7 & 19 & 66 & - & - & - & - \\
\hline \multirow{2}{*}{ Route 3} & Pipe Segment & 16 & 15 & 14 & 13 & 12 & 11 & 7 & 6 & 2 & 1 & - \\
\hline & Length [m] & 23.4 & 23.8 & 18.5 & 31.1 & 26.2 & 31 & 37.4 & 35.7 & 19 & 66 & - \\
\hline \multirow{2}{*}{ Route 4} & Pipe Segment & 19 & 18 & 17 & 13 & 12 & 11 & 7 & 6 & 2 & 1 & - \\
\hline & Length [m] & 22.5 & 23 & 81.8 & 31.1 & 26.2 & 31 & 37.4 & 35.7 & 19 & 66 & - \\
\hline \multirow{2}{*}{ Route 5} & Pipe Segment & 23 & 22 & 21 & 20 & 1 & - & - & - & - & - & - \\
\hline & Length [m] & 23.5 & 22 & 32.3 & 28.5 & 66 & - & - & - & - & - & - \\
\hline \multirow{2}{*}{ Route 6} & Pipe Segment & 28 & 27 & 26 & 25 & 24 & 20 & 1 & - & - & - & - \\
\hline & Length [m] & 24 & 23.9 & 22.7 & 36 & 35 & 28.5 & 66 & - & - & - & - \\
\hline \multirow{2}{*}{ Route 7} & Pipe Segment & 34 & 33 & 32 & 31 & 30 & 29 & 25 & 24 & 20 & 1 & - \\
\hline & Length [m] & 22.8 & 23 & 20.9 & 29.9 & 24.9 & 34.2 & 36 & 35 & 28.5 & 66 & - \\
\hline \multirow{2}{*}{ Route 8} & Pipe Segment & 38 & 37 & 36 & 35 & 31 & 30 & 29 & 25 & 24 & 20 & 1 \\
\hline & Length [m] & 23.8 & 22 & 68.9 & 33.6 & 29.9 & 24.9 & 34.2 & 36 & 35 & 28.5 & 66 \\
\hline
\end{tabular}

${ }^{a}$ On the top line, 1 denotes the end branch (last pipe segment) for each route and the numbers to the right of it the successive pipe segments from the last one to the root node (or heat source).

Optimal pipe diameters, as found for a low-energy DH network connected to consumers by way of Substation Type 1 are shown, together with final pressure-drop values, in Table 2 . The order of presentation there is the same as in Table 1. 
Table 2. Optimal pipe diameters and the pressure drop values observed, shown for Substation Type 1.

\begin{tabular}{|c|c|c|c|c|c|c|c|c|c|c|c|c|}
\hline & & 1 & 2 & 3 & 4 & 5 & 6 & 7 & 8 & 9 & 10 & 11 \\
\hline \multirow{2}{*}{ Route 1} & Pipe Diameter [mm] & 10 & 15 & 20 & 37.2 & 70.3 & - & - & - & - & - & \\
\hline & Pressure Drop [bar] & 3.4 & 1.3 & 1.2 & 0.5 & 0.2 & - & - & - & - & - & - \\
\hline \multirow{2}{*}{ Route 2} & Pipe Diameter [mm] & 10 & 15 & 20 & 37.2 & 37.2 & 37.2 & 70.3 & - & - & . & - \\
\hline & Pressure Drop [bar] & 3.2 & 1.3 & 0.7 & 0.6 & 0.6 & 0.5 & 0.2 & - & - & - & - \\
\hline \multirow{2}{*}{ Route 3} & & 10 & 15 & 20 & 37.2 & 37.2 & 37.2 & 37.2 & 37.2 & 37.2 & 70.3 & \\
\hline & Pressure Drop [bar] & 3.3 & 1.4 & 0.5 & 0.2 & 0.2 & 0.2 & 0.6 & 0.6 & 0.5 & 0.2 & - \\
\hline \multirow{2}{*}{ Route 4} & ameter [mm] & 15 & 20 & 20 & 37.2 & 37.2 & 37.2 & 37.2 & 37.2 & 37.2 & 70.3 & - \\
\hline & Press & 0.4 & 0.3 & 2.3 & 0.2 & 0.2 & 0.2 & 0.6 & 0.6 & 0.5 & 0.2 & - \\
\hline \multirow{2}{*}{ Route 5} & ameter [mm] & 10 & 15 & 20 & 37.2 & 70.3 & - & - & - & - & - & - \\
\hline & Pressu & 3.3 & 1.3 & 0.9 & 0.8 & 0.2 & - & - & - & - & - & - \\
\hline \multirow{2}{*}{ Route 6} & Pipe & 10 & 15 & 20 & 37.2 & 37.2 & 37.2 & 70.3 & - & - & - & - \\
\hline & Pressu & 3.4 & 1.4 & 0.6 & 0.6 & 0.6 & 0.8 & 0.2 & - & - & - & - \\
\hline \multirow{2}{*}{ Route 7} & ameter [mm] & 11.6 & 15 & 20 & 37.2 & 37.2 & 37.2 & 37.2 & 37.2 & 37.2 & 70.3 & - \\
\hline & Press & 1.5 & 1.3 & 0.6 & 0.2 & 0.2 & 0.3 & 0.6 & 0.6 & 0.8 & 0.2 & - \\
\hline \multirow{2}{*}{ Route 8} & Pipe Dian & 10 & 15 & 37.2 & 37.2 & 37.2 & 37.2 & 37.2 & 37.2 & 37.2 & 37.2 & 70.3 \\
\hline & Pressure Drop [bar] & 3.3 & 1.3 & 0.1 & 0.1 & 0.2 & 0.2 & 0.3 & 0.6 & 0.6 & 0.8 & 0.2 \\
\hline
\end{tabular}

Optimal pipe diameters found for a low-energy DH network connected to consumers by way of Substation Type 2 are shown, together with final pressure-drop values, in Table 3, the order of presentation there too being the same as in Table 1.

Table 3. Optimal pipe diameters and pressure drop values as observed for Substation Type 2.

\begin{tabular}{|c|c|c|c|c|c|c|c|c|c|c|c|c|}
\hline & & 1 & 2 & 3 & 4 & 5 & 6 & 7 & 8 & 9 & 10 & 11 \\
\hline \multirow{2}{*}{ Route 1} & Pipe Diameter [mm] & 15 & 26 & 26 & 70.3 & 70.3 & - & - & - & - & - & - \\
\hline & Pressure Drop [bar] & 4.2 & 0.5 & 1.5 & 0.0 & 0.5 & - & - & - & - & - & - \\
\hline \multirow{2}{*}{ Route 2} & Pipe Diameter [mm] & 15 & 37.2 & 37.2 & 37.2 & 37.2 & 70.3 & 70.3 & - & - & - & - \\
\hline & Pressure Drop [bar] & 4.0 & 0.1 & 0.2 & 1.6 & 1.7 & 0.0 & 0.5 & - & - & - & - \\
\hline \multirow{2}{*}{ Route 3} & Pipe Diameter [mm] & 26 & 37.2 & 37.2 & 37.2 & 37.2 & 37.2 & 37.2 & 37.2 & 70.3 & 70.3 & - \\
\hline & Pressure Drop [bar] & 0.3 & 0.1 & 0.2 & 0.6 & 0.6 & 0.8 & 1.6 & 1.7 & 0.0 & 0.5 & - \\
\hline \multirow{2}{*}{ Route 4} & Pipe Diameter [mm] & 20 & 37.2 & 37.2 & 37.2 & 37.2 & 37.2 & 37.2 & 37.2 & 70.3 & 70.3 & - \\
\hline & Pressure Drop [bar] & 0.9 & 0.1 & 0.7 & 0.6 & 0.6 & 0.8 & 1.6 & 1.7 & 0.0 & 0.5 & - \\
\hline \multirow{2}{*}{ Route 5} & Pipe Diameter [mm] & 15 & 20 & 37.2 & 70.3 & 70.3 & - & - & - & - & - & - \\
\hline & Pressure Drop [bar] & 4.1 & 1.9 & 0.3 & 0.1 & 0.5 & - & - & - & - & - & - \\
\hline \multirow{2}{*}{ Route 6} & Pipe Diameter [mm] & 20 & 20 & 37.2 & 37.2 & 37.2 & 70.3 & 70.3 & - & - & - & - \\
\hline & Pressure Drop [bar] & 1.0 & 2.0 & 0.2 & 1.7 & 1.7 & 0.1 & 0.5 & - & - & - & - \\
\hline \multirow{2}{*}{ Route 7} & Pipe Diameter [mm] & 26 & 37.2 & 37.2 & 37.2 & 37.2 & 37.2 & 37.2 & 37.2 & 70.3 & 70.3 & - \\
\hline & Pressure Drop [bar] & 0.3 & 0.1 & 0.2 & 0.7 & 0.6 & 1.0 & 1.7 & 1.7 & 0.1 & 0.5 & - \\
\hline \multirow{2}{*}{ Route 8} & Pipe Diameter [mm] & 37.2 & 37.2 & 37.2 & 37.2 & 37.2 & 37.2 & 37.2 & 37.2 & 37.2 & 70.3 & 70.3 \\
\hline & Pressure Drop [bar] & 0.1 & 0.1 & 0.6 & 0.3 & 0.7 & 0.6 & 1.0 & 1.7 & 1.7 & 0.1 & 0.5 \\
\hline
\end{tabular}


Booster pumps with a head lift capacity of 3.8 bar were installed at the start of the series of pipe segments located at the street level (start of the series of pipe segments at the third level in the reverse-hierarchy of pipe segment, in accordance with the order given in Table 4). Pipe segments 3 and 21, which belonged to Routes 1 and 5, respectively, were not equipped with booster pumps, since otherwise the maximum static pressure there would have exceeded the system's maximum allowable static pressure, which was defined as design limit of 10 bara.

Table 4. Optimal pipe diameters and the pressure drop values observed, for Substation Type 2, together with additional booster pumps, in the DH network.

\begin{tabular}{|c|c|c|c|c|c|c|c|c|c|c|c|c|}
\hline & & 1 & 2 & 3 & 4 & 5 & 6 & 7 & 8 & 9 & 10 & 11 \\
\hline \multirow{2}{*}{ Route 1} & Pipe Diameter [mm] & 15 & 20 & 37.2 & 54.5 & 70.3 & - & - & - & - & - & - \\
\hline & Pressure Drop [bar] & 4.2 & 1.9 & 0.3 & 0.1 & 0.5 & - & - & - & - & - & - \\
\hline \multirow{2}{*}{ Route 2} & Pipe Diameter [mm] & 15 & 20 & 26 & 37.2 & 37.2 & 54.5 & 70.3 & - & - & - & - \\
\hline & Pressure Drop [bar] & 4.0 & 2.0 & 0.9 & 1.6 & 1.7 & 0.1 & 0.5 & - & - & - & - \\
\hline \multirow{2}{*}{ Route 3} & Pipe Diameter [mm] & 20 & 20 & 20 & 37.2 & 37.2 & 37.2 & 37.2 & 37.2 & 54.5 & 70.3 & - \\
\hline & Pressure Drop [bar] & 1.0 & 2.0 & 2.5 & 0.6 & 0.6 & 0.8 & 1.6 & 1.7 & 0.1 & 0.5 & - \\
\hline \multirow{2}{*}{ Route 4} & Pipe Diameter [mm] & 15 & 26 & 37.2 & 37.2 & 37.2 & 37.2 & 37.2 & 37.2 & 54.5 & 70.3 & - \\
\hline & Pressure Drop [bar] & 3.9 & 0.5 & 0.7 & 0.6 & 0.6 & 0.8 & 1.6 & 1.7 & 0.1 & 0.5 & 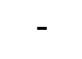 \\
\hline \multirow{2}{*}{ Route 5} & Pipe Diameter [mm] & 15 & 20 & 37.2 & 54.5 & 70.3 & - & - & - & - & - & - \\
\hline & Pressure Drop [bar] & 4.1 & 1.9 & 0.3 & 0.3 & 0.5 & - & - & - & - & - & - \\
\hline \multirow{2}{*}{ Route 6} & Pipe Diameter [mm] & 15 & 20 & 37.2 & 37.2 & 37.2 & 54.5 & 70.3 & - & - & - & - \\
\hline & Pressure Drop [bar] & 4.2 & 2.0 & 0.2 & 1.7 & 1.7 & 0.3 & 0.5 & - & - & - & - \\
\hline \multirow{2}{*}{ Route 7} & Pipe Diameter [mm] & 15 & 37.2 & 37.2 & 37.2 & 37.2 & 37.2 & 37.2 & 37.2 & 54.5 & 70.3 & - \\
\hline & Pressure Drop [bar] & 4.0 & 0.1 & 0.2 & 0.7 & 0.6 & 1.0 & 1.7 & 1.7 & 0.3 & 0.5 & - \\
\hline \multirow{2}{*}{ Route 8} & Pipe Diameter [mm] & 15 & 37.2 & 37.2 & 37.2 & 37.2 & 37.2 & 37.2 & 37.2 & 37.2 & 54.5 & 70.3 \\
\hline & Pressure Drop [bar] & 4.1 & 0.1 & 0.6 & 0.3 & 0.7 & 0.6 & 1.0 & 1.7 & 1.7 & 0.3 & 0.5 \\
\hline
\end{tabular}

The heat loss observed in the DH network connected to Substation Type 2 resulted in an 8\% increase as compared with Substation Type 1 equipped at substation of each consumer, while 6\% increase observed when booster pumps were installed at the DH network.

\subsection{Dynamic Analyses}

In these analyses the low-energy DH network was considered as supplying heat to low-energy buildings, each equipped with a substation having a 1201 storage tank. Five different scenarios were generated per each occupancy ratio of $25 \%, 50 \%$, and $75 \%$, using a time step of 10 minutes within a time range of 8 hours. Here the occupancy ratio refers to the consumers pre- 
sent in the DH network in vacation periods. The return temperature observed at the heat source varied appreciably with changes in consumer consumption profiles in the case of the branched network layout. For the looped layout, in contrast, the return temperature was found to be constant at about $25^{\circ} \mathrm{C}$, independent of the dynamic behaviour of the consumers and of the occupancy ratio. In addition, the operation intensity of the bypasses could be followed on the basis of the ratio of bypass flow to total flow observed in the branched distribution network, as shown in Table 5.Table 5. Ratio of bypass flow to total flow, as observed for different scenarios.

\begin{tabular}{|c|c|c|c|c|c|c|c|c|c|c|c|c|c|c|c|}
\hline & $25 \quad 1$ & 252 & 253 & 254 & 255 & 501 & $50 \_2$ & 503 & 504 & 505 & $75 \_1$ & $75 \quad 2$ & 753 & $75 \quad 4$ & 75 \\
\hline $\begin{array}{c}\text { Mean } \\
\text { Standard }\end{array}$ & 14.0 & 14.1 & 11.1 & 16.2 & 11.3 & 3.7 & 4.6 & 4.2 & 3.5 & 4.2 & 1.6 & 1.5 & 1.4 & 1.4 & 1.3 \\
\hline Deviation & 2.4 & 2.7 & 2.8 & 2.6 & 2.7 & 1.3 & 2.4 & 2.6 & 1.2 & 1.0 & 1.4 & 0.8 & 0.9 & 1.4 & 0.9 \\
\hline
\end{tabular}

The heat loss from the DH network and the heat supplied to it, as observed in simulations of the branched and the looped layouts, respectively, are given in Table 6 and Table 7.

Table 6. Heat loss from the DH network and heat supplied to the DH network, as observed for a branched layout.

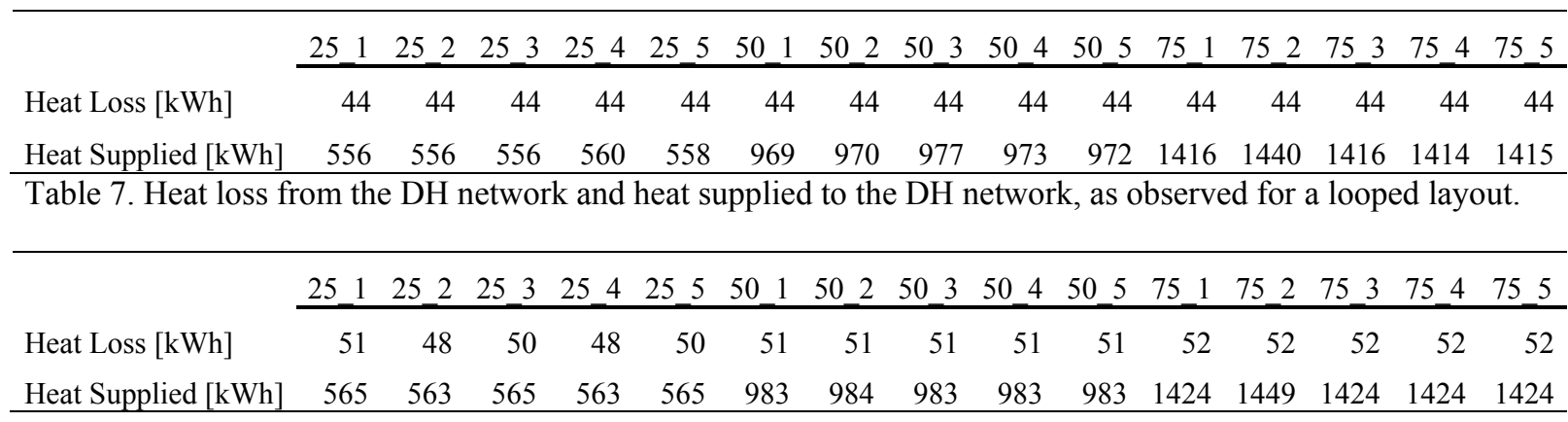
The degree-minutes found in analyses of scenario S25_3 regarding unsatisfied heatdemanding nodes there are shown in Figure 7. Changes over time in the heat demand and in supply temperatures in the looped layout are shown in Figure 8. The supply temperatures observed for the same heat demand scenario, but involving a branched layout, are shown in Figure 9. 


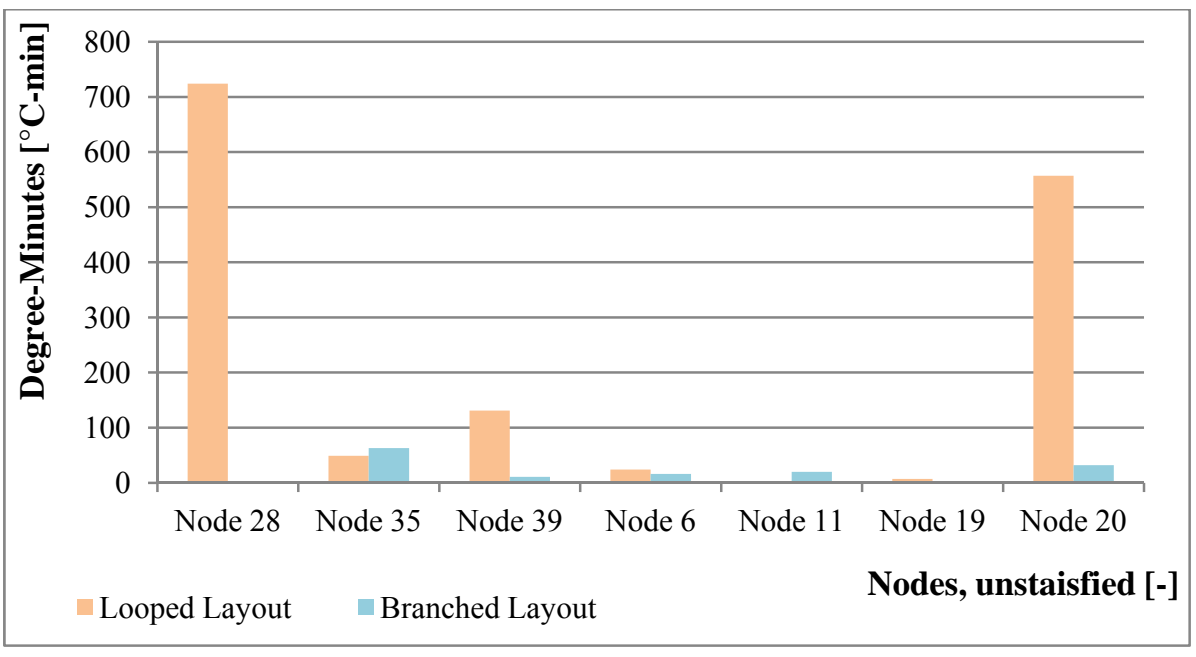

Figure 7. Degree-minutes for the unsatisfied nodes alone, for scenario S25_3.

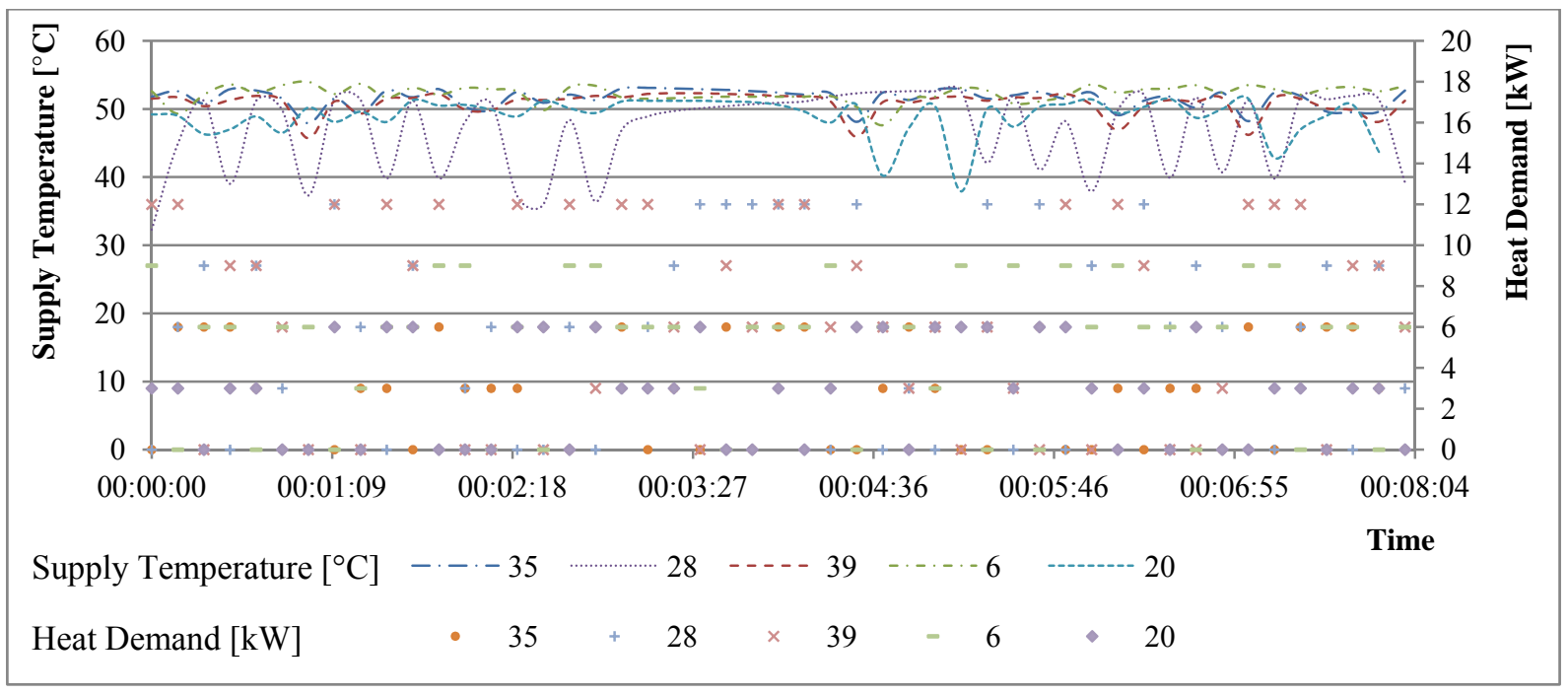

Figure 8. Changes over time in the supply temperature and in the DHW heat demand, as shown for the unsatisfied heat-consuming nodes $(35,28,39,6$, and 20), for the looped layout when using scenario S25_3.

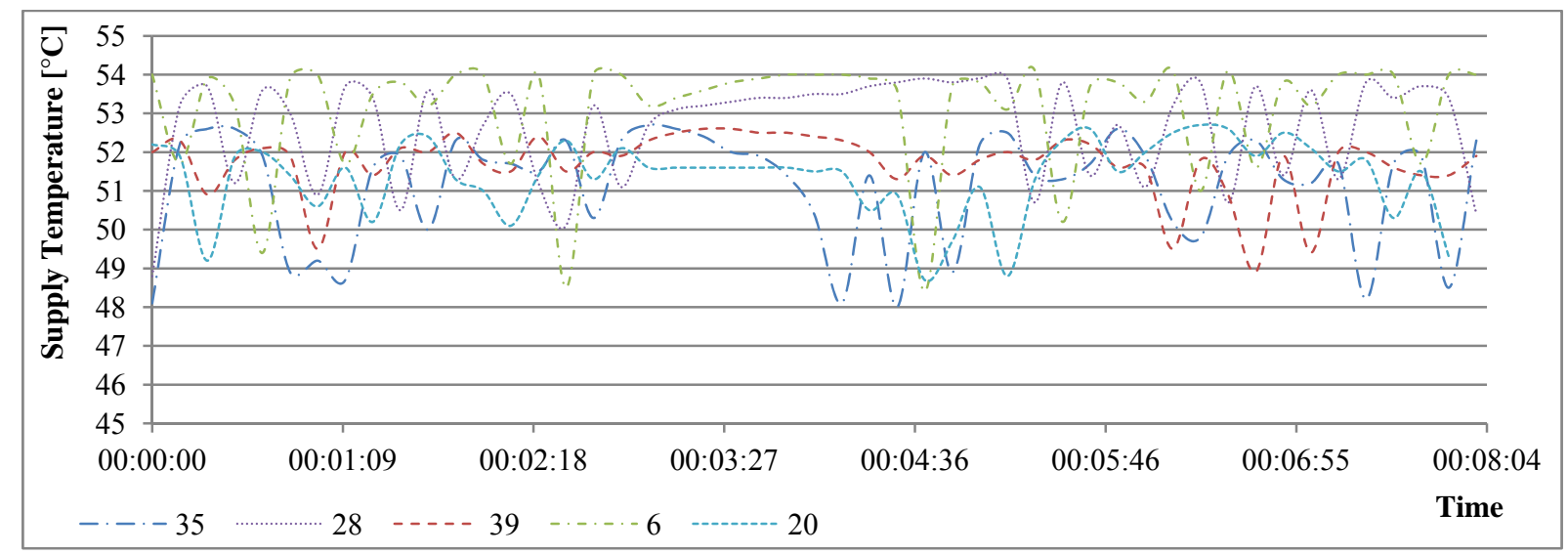

Figure 9. Changes over time in the supply temperature of the unsatisfied heat-consuming nodes $(35,28,39,6$, and 20), for the branched layout when using scenario S25_3. 
Figure 10 shows three different flow configurations, and the variable pressure differences observed, in a simulation involving use of the input of scenario S25_3.

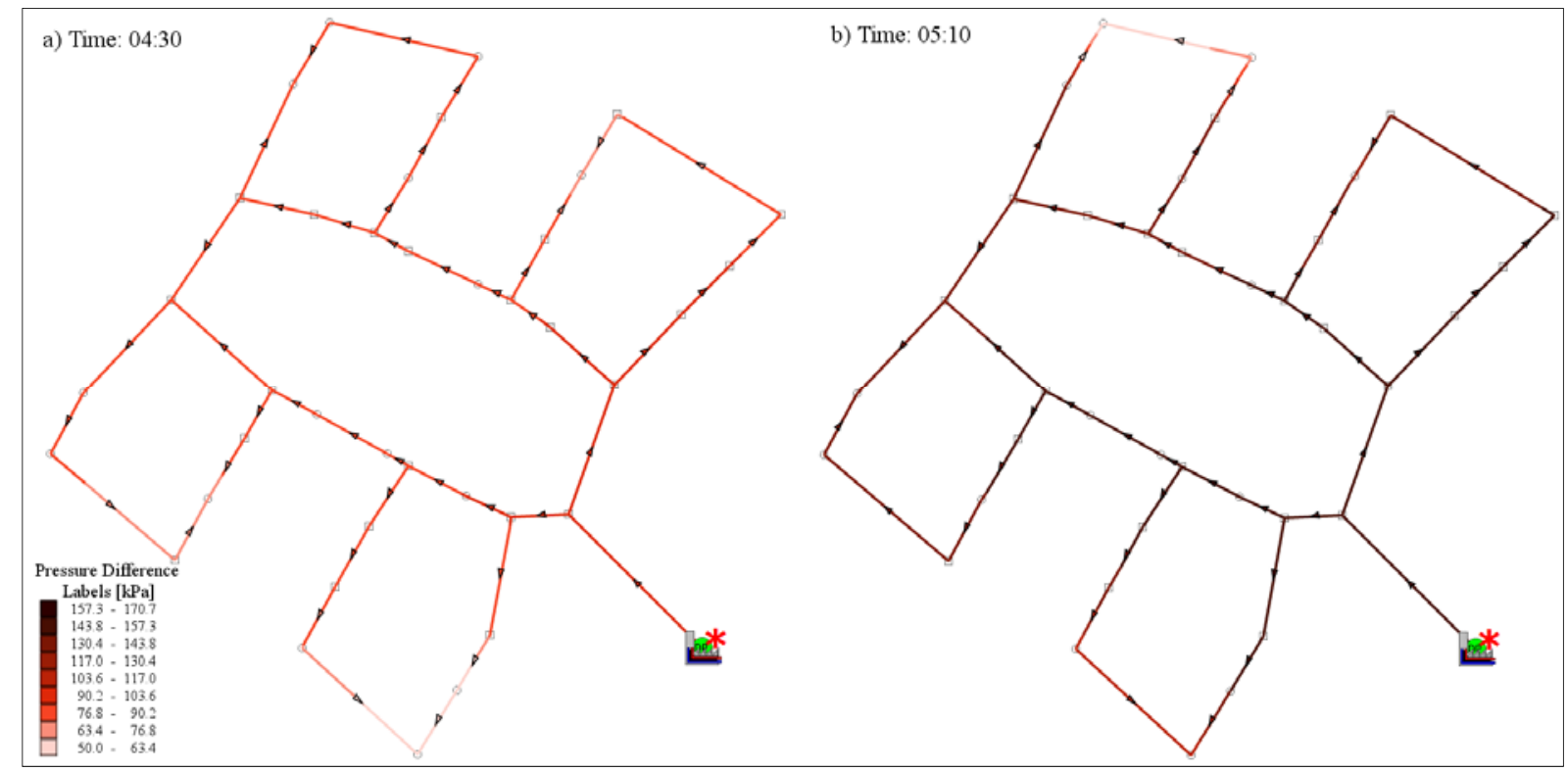

Figure 10. Simulation results for pressure difference observed in the distribution network at times 04:30, and $05: 10$, respectively.

\section{DISCUSSION}

The study provides analyses and comparisons of different low-energy DH systems, particularly as regards substation types, booster pumps, and the type of network and network layouts involved in the case study carried out concerned with Trekroner, a suburban area located in the Municipality of Roskilde in Denmark.

\subsection{Substations Types and Booster Pumps}

Pipe segments of differing level were found to differ considerably in the degree of variation in the heat load values that were observed due to different heat demand values defined dependent on the substation type established at each consumer site. For example, the heat load of the successor pipe segments of the root nodes varied by a ratio of $30 \%$, whereas the heat load of the predecessor pipe segments of the leaf nodes varied by a ratio of $70 \%$, comparing the Substation Type 1 and 2 established in each consumer site with the same branched network layout 
formed in the case area (Figure 6). The differing variation ratios of the heat load values observed dependent on differing level of pipe segment are based on the simultaneity factor being dependent upon the cumulative number on consumers involved, since the simultaneity factor decreases as the number of consumers affected increases. In DH networks generally, the number of pipe segments in the end branches is much greater than the number of main transmission pipe segments that supply heat to the smaller branches that are closer to the leaf nodes. Thus, it is highly desirable that consumers in a DH network each be provided with a substation having a storage tank, in order to prevent heat loss occurring excessively at the pipe segments close to the end branches due to their being preponderance.

Although the optimization method described in studies [16, 22] applied to networks for each substation type, the effects of heat load were found to be significant on optimal diameter obtained at each of the pipe segment, as can be seen in Table 2, and Table 3, because of the substation each consumer was provided with being equipped with a storage tank (Substation Type 1) due to reduction obtained at the flow requirements of consumers further. The booster pumps located at the start of the pipe segments in each street had a similar function, their making possible a reduction in pipe diameters in networks supplying heat to substations without storage tanks, although in terms of the degree of heat loss from the DH network that took place they were not competitive with DH networks that supplied heat to substations provided with a storage tank.

\subsection{Network Layouts}

In the study, excessive drops in the supply temperature were analysed by means of dynamic simulations of periods in the summer months, branched network layouts being compared with looped ones. Different heat-load scenarios involving the partial absence of consumers, as well as differing degrees of simultaneity in heat consumption, resulted in differences in the manner of operation of the $\mathrm{DH}$ network, for example differing return temperatures at the heat source 
in various of the branched layouts, and differing supply temperatures for heat-demanding consumers in response to the level of heat demand, in various of the looped layouts. A lesser presence of consumers resulted in increased variance in operation of the DH system as dynamic response of differing scenarios of heat demand profiles. When only $25 \%$ of the consumers were present, for example, results for a branched and for a looped layout differed considerably, particularly in regard to return temperatures in the former case and to supply temperatures (in terms of degree-minutes) in the latter case. When $50 \%$ or $75 \%$ of the consumers were present, operation of the DH system was less dependent upon the heat demand profiles of consumers. This could be noted in changes in return temperatures and in degree-minute results for branched and for looped layouts, respectively, using different scenarios of consumers' heat demand profiles as input in dynamic analyses.

Regarding heat losses as determined in analyses, results in the branched networks for all of the scenarios were very similar. The bypasses at the leaf nodes circulated supply water when it reached a temperature of $50{ }^{\circ} \mathrm{C}$, but did not allow the supply temperature to be cooled down any further. This resulted in a constant heat loss of $44 \mathrm{kWh}$ from the $\mathrm{DH}$ network while higher presence of consumers resulted in increased necessity of heat supply from the heat source (Table 6). Slight differences between scenarios in the heat supplied were observed for each of the three consumer presence levels. For the looped layout, variance was more likely to be observed for the heat loss from the DH network, mainly at the low consumer presence level of $25 \%$ (as can be seen in Table 7), though not for the heat supply, such as had been observed in the branched layout. Heat loss was found to be more likely to occur from the return line when a branched layout was involved, due to mixing of the supply heat carrier medium with the return heat carrier medium occurring by means of circulation through the bypasses, and from the supply line when the layout was a looped one, due to long waiting times for the supply heat carrier medium then. However one should note that the overall heat loss 
from the supply line is considerably higher than the overall heat loss from the return line, regardless of the network layout.

The long waiting times for the supply heat carrier medium that the low heat demand of consumers during the summer period brought about led to an appreciably greater lowering of the supply temperature for the looped than for the branched layout. The long waiting times also resulted in the failure of consumers' supply temperature needs to be fully met. It was found also that the heat loss from the DH network was greater in a looped layout than in a branched layout under these circumstances, as can be seen in Table 6 and Table $7 .$.

It can be useful to assess on the basis of degree-minutes calculations the extent to which the needs of heat-demanding consumers are satisfied, as illustrated in Figure 7. High values there were obtained under looped layout conditions for various heat-demanding customers, suggesting them to be confronted to no more than a slight extent or for only short durations with inadequate supply temperatures, whereas others were confronted with continuously inadequate supply temperatures, low in level and for extended periods of time. Figure 8 and Figure 9 illustrate a lack of satisfaction of the needs of heat-demanding customers under looped and under branched layout conditions, respectively, in dynamic simulations involving use of scenario S25_3. For the looped layout the supply temperature was observed to reach down to a level of about $40{ }^{\circ} \mathrm{C}$, whereas for the branched layout it sometimes reached a level of about 50 ${ }^{\circ} \mathrm{C}$.

One should take note of the fact that sometimes operational changes in the DH network occurred such that in certain parts of the network some of the high-demand profiles could result in differences in the flow direction occurring. As can be seen in Figure 10, the direction of flow can change in a manner such that some pipe segments show a change in direction of flow within a given simulation, analysed by use of the scenario S25_3. One should also note that neutral points can be formed when at a particular point in a local loop two separate flows are 
directed at each other. Neutral points could be observed in separate local loops at two different steps time wise, as can be observed in Figure 10. Changing heat demand profiles led to the relocation of neutral points while the $\mathrm{DH}$ network was in operation.

\section{CONCLUSIONS}

The paper has considered various technical aspects of low-energy DH systems in detail; taking up in particular different substation types and network layouts, as well as various substation types. The aim here has not been to adjudge what the best possible solution is to any of the problems taken up, but rather to explore the effects of each of the parameters of interest that are considered here can have on a variety of different matters of interest here. One such matter is that of determining in an adequate way the heat load in different parts of a lowenergy district heating system and at different points in time. Another is that of equipping the substations of individual consumers with a storage tank that can result in a significant reduction in the pipe dimensions needed in the network in question, especially at end branches of the network, which are in preponderance in most district heating systems. Employing a simultaneity factor at each level of a pipe segment is also shown to be useful, in particular for avoiding over-dimensioning, since the consumers in a district do not all consume heat at the same time. Use of booster pumps and their relevance to avoidance of over-dimensioning in cases in which the maximum static pressure allowable is very limited is also taken up, as are important characteristics of different network layouts, the special usefulness of looped network layouts in areas of dense population and the superiority of branched DH networks with bypasses at leaf-nodes in matters relating to heat loss and the satisfaction of consumer needs. Specific methods proposed here are seen as being of potential interest in the planning of future energy structures for supplying heat to low-energy buildings. The study reported on, concerning a geographical case area and a reference house there of a particular type serves as a basis for considering the various topics of concern here in concrete terms. Use is made in 
various analyses of the software $\mathrm{Be} 06$. There are obvious limitations to the focus taken in the study, but it is seen as providing a sensible basis for further study. One could investigate, for example, low-energy DH systems designed for different house types. Also, the effects of booster pumps on pipe dimensioning should be investigated for large networks, due to their possible applicability to the allowed pressure difference between supply and return lines in large networks. One can also study complex network structures involving both the branched and the looped network together, can be appropriate.

\section{ACKNOWLEDGEMENTS}

The work presented in the paper was aided to a very significant extent by based on the data and the map provided by Roskilde Forsyning A/S.

\section{REFERENCES}

[1] T.N. Veziroğlu, S. Şahin, 21st Century's energy: Hydrogen energy system, Energy Conversion and Management. 49 (2008) 1820-1831.

[2] H. Arif, A review on energetic, exergetic and exergoeconomic aspects of geothermal district heating systems (GDHSs), Energy Conversion and Management. 51 (2010) 2041-2061.

[3] U. Persson, S. Werner, Heat distribution and the future competitiveness of district heating, Applied Energy. 88 (2011) 568-576.

[4] H. Lund, B. Möller, B.V. Mathiesen, A. Dyrelund, The role of district heating in future renewable energy systems, Energy. 35 (2010) 1381-1390.

[5] H. Lund, B.V. Mathiesen, Energy system analysis of 100\% renewable energy systemsThe case of Denmark in years 2030 and 2050, Energy. 34 (2009) 524-531.

[6] H. Lund, Renewable energy systems: the choice and modeling of $100 \%$ renewable solutions, Elsevier, Burlington, USA, 2010. 
[7] I. Dincer, A. Hepbasli, District energy systems, in: B.L. Capehart (Ed), Encyclopedia of Energy Engineering and Technology - 3 Volume Set (Print Version), Boca Raton, FL, CRC Press, 2007, pp. 316-331.

[8] C.H. Christiansen, J. Worm, H. Jørgensen, J.E. Thorsen, J. Bennetsen, C.T. Larsen et al., Demonstration of low energy district heating system for low energy building in Ringgårdens Afd. 34 in Lystrup (in Danish), Copenhagen, Teknologisk Institute, Maj 2011, 104 p. Report No: EUDP 2008-II. <http://www.ibe.dtu.dk/upload/institutter/byg/publications/rapporter/bygr250.pdf> [accessed 06.01.2012].

[9] J.E. Thorsen, C.H. Christiansen, M. Brand, P.K. Olesen, C.T. Larsen, Experiences on lowtemperature district heating in Lystrup - Denmark, in: International Conference on District Energy, Portorož, Slovenia, 2011 March 20-22.

[10] C.H. Christiansen, O. Paulsen, B. Bøhm, J.E. Thorsen, C. Ting Larsen, B.K. Jepsen et al., Development and demonstration of low-energy district heating for low-energy buildings. Main report and appendices (in Danish), Teknologisk Institut, March 2009, Report No: EFP 2007. <www.teknologisk.dk/_root/media/34221_EFP\%202007.pdf> [accessed 06.01.2012] [11] SSE, SSE zero carbon home development. <http://www.ssezerocarbonhomes.com/> [accessed 10.01.2012].

[12] R. Wiltshire, Low temperature district energy systems, in: Urban Energy Conference, Debrecen, Hungary, 2011 October 13-14, pp. 91-99.

[13] P.K. Olsen, H. Lambertsen, R. Hummelshøj, B. Bøhm, C.H. Christiansen, S. Svendsen et al., A new low-temperature district heating system for low-energy buildings, in: The 11th International Symposium on District Heating and Cooling, Reykjavik, Iceland, 2008 Aug 31 - Sep 2. 
[14] O. Paulsen, J. Fan, S. Furbo, J.E. Thorsen, Consumer Unit for Low Energy District Heating Net, in: The 11th International Symposium on District Heating and Cooling, Reykjavik, Iceland, 2008 Aug 31 - Sep 2.

[15] Y. Li, L. Fu, S. Zhang, Y. Jiang, Z. Xiling, A new type of district heating method with co-generation based on absorption heat exchange (co-ah cycle), Energy Conversion and Management. 52 (2011) 1200-1207.

[16] H.İ. Tol, S. Svendsen, Improving the Dimensioning of Piping Networks and Network Layouts in Low-Energy District Heating Systems Connected to Low-Energy Buildings: A case study in Roskilde, Denmark, Energy. In Press.

[17] N. Y1ldırım, M. Toksoy, G. Gökçen, Piping network design of geothermal district heating systems: Case study for a university campus, Energy. 35 (2010) 3256-3262.

[18] A.C. Şener, G. Gökçen, Pipelines and Piping Network in Geothermal District Heating Systems, in: IEEES - Proceedings of the First International Exergy, Energy and Environment Symposium, İzmir, Turkey, 2003 July 13-17.

[19] J. Overgaard, S. Knudsen, District heating networks - choosing the right pipe dimensions, DBDH. 2006; 1. <http://dbdh.dk/images/uploads/pdf-distribution/district-heatingnetworkschoosing-the-right.pdf $>$ [accessed 10.01.2011].

[20] A. Benonysson, B. Bøhm, H.F. Ravn, Operational optimization in a district heating system, Energy Conversion and Management. 36 (1995) 297-314.

[21] R.L. Sanks, Flow in conduits, in: R.L. Sanks, Pumping station design, Boston, USA, Elsevier Gulf, 1998, pp. 33-39.

[22] H.İ. Tol, S. Svendsen, Design of low-energy district heating system for a settlement with low-energy buildings, in: $3^{\text {rd }}$ International Symposium on Environmental Management, Zagreb, Croatia, 2011 Oct 26-28, pp. 166-171. 
[23] H.İ. Tol, S. Svendsen, Determination of optimum network layout for low-energy district heating systems with different substation types, in: The Third International Renewable Energy Congress, Hammamet, Tunisia, 2011 Dec 20-22, pp. 179-184.

[24] S. Aggerholm, K.E. Thomsen, K.B. Wittchen, Implementation of the EPBD in Denmark - Status in November 2010, Aalborg, Denmark, Danish Building Research Institute, 2011,13 p.

[25] V.D. Stevanovic, B. Zivkovic, S. Prica, B. Maslovaric, V. Karamarkovic, V. Trkulja, Prediction of thermal transients in district heating systems, Energy Conversion and Management. 50 (2009) 2167-2173.

[26] I. Gabrielaitiene, B. Bøhm, B. Sunden, Modelling temperature dynamics of a district heating system in Naestved, Denmark-A case study, Energy Conversion and Management 48 (2007) 78-86.

[27] H. Boysen, J.E. Thorsen, Hydraulic balance in a district heating system, Danfoss, 2011, 8 p. <http://heating.danfoss.com/PCMPDF/VFLRC202_Hydraulic_balance.pdf $>$ [accessed 10.01.2012].

[28] Danfoss, 8 steps - control of heating system. < http://heating.danfoss.com/Content/61078BB5-1E17-4CA2-AC498A7CAC2BA687_MNU17424997_SIT54.html> [accessed 10.11.2011].

[29] M. Brand, A. Dalla Rosa, S. Svendsen, Performance of low temperature district heating systems for low energy houses, in: Annex 49 "Low Exergy Systems for High-Performance Building and Communities", Munich, Germany, 2010 Oct 19-21, pp. 174-183.

[30] M. Brand, J.E. Thorsen, S. Svendsen, C.H. Christiansen, A direct heat exchanger unit used for domestic hot water supply in a single-family house supplied by low energy district heating, in: The 12th International Symposium on District Heating and Cooling, Talinn, Estonia, 2010 Sep 5-7, pp. 60-68. 
[31] H. Li, A. Dalla Rosa, S. Svendsen, Design of low temperature district heating network with supply water recirculation, in: The 12th International Symposium on District Heating and Cooling, Talinn, Estonia, 2010 Sep 5-7, pp. 73-80.

[32] A. Dalla Rosa, H. Li, S. Svendsen, Steady state heat losses in pre-insulated pipes for lowenergy district heating, in: The 12th International Symposium on District Heating and Cooling, Talinn, Estonia, 2010 Sep 5-7, 81-89.

[33] A. Dalla Rosa, H. Li, S. Svendsen, Method for optimal design of pipes for low-energy district heating, with focus on heat losses, Energy. 36 (2011) 2407-2418.

[34] M. Bernot, V. Caselles, J. Morel, Branched transportation networks, Springer, Berlin Heidelberg New York, 2007.

[35] R.P. Lejano, Optimizing the layout and design of branched pipeline water distribution systems, Irrigation and Drainage Systems. 20 (2006) 125-137.

[36] C. González, B. Macarulla, D. Sallán, Recursive design of pressurized branched irrigation networks, Journal of Irrigation and Drainage Engineering. 137 (2010) 375-382.

[37] J.W. Davidson, Learning program for the design of layout geometry of rectilinear looped water distribution networks. PhD Thesis. University of Manitoba, Manitoba, Canada, 1998.

[38] A. Yazdani, R.A. Otoo, P. Jeffrey, Resilience enhancing expansion strategies for water distribution systems: A network theory approach, Environmental Modelling \& Software. 26 (2011) 1574-1582.

[39] Maunder C, editor. Termis help manual [disk]. Version 2.10. Denmark: Birkerød; 2010. 7-Technologies A/S.

[40] F. Zheng, A.R. Simpson, A.C. Zecchin, A combined NLP-differential evolution algorithm approach for the optimization of looped water distribution systems, Water Resources Research. 47, W08531, doi:10.1029/2011WR010394. 
[41] B. Xu, L. Fu, H. Di, Field investigation on consumer behavior and hydraulic performance of a district heating system in Tianjin, China, Building and Environment. 44 (2009) 249-259.

[42] H.V. Larsen, B. Bøhm, M. Wigbels, A comparison of aggregated models for simulation and operational optimisation of district heating networks, Energy Conversion and Management. 45 (2004) 1119-1139.

[43] Å. Nystedt, J. Shemeikka, K. Klobut, Case analyses of heat trading between buildings connected by a district heating network, Energy Conversion and Management. 47 (2006) $3652-3658$

[44] A. Durmayaz, An application of the degree-hours method to estimate the residential heating energy requirement and fuel consumption in Istanbul, Energy. 25 (2000) 1245-1256. 